\title{
Conversion of lutein into dehydroretinol by the freshwater fish, Saccobranchus fossilis
}

\author{
By A. B. BARUA, H. TOMBI SINGH* AND R. C. DAS $\dagger$ \\ Department of Chemistry, Gauhati University, \\ Gauhati-I4, Assam, India
}

(Received 27 March $1972-$ Accepted 29 November 1972)

\begin{abstract}
I. The vitamin A content of Saccobranchus fossilis kept on a diet of rice and meat gradually decreased and became negligible at the end of $3-5$ months.

2. $S$. fossilis initially contained more dehydroretinol than retinol; administration of $\beta$-carotene or zeaxanthin to the vitamin A-depleted fish did not result in an accumulation of dehydroretinol in the liver. On the other hand, when lutein was administered by mouth or subcutaneous injection, it was converted into dehydroretinol.
\end{abstract}

Although it has been conclusively proved that $\beta$-carotene and several related carotenoids with at least one unsubstituted $\beta$-ionone ring act as provitamins $A$, the origin of dehydroretinol (vitamin $A_{2}$ ), which preponderates over retinol in most freshwater fish, is not clearly known (Ganguly \& Murthy, 1967). Long before the structure of vitamin $A_{2}$ was proved to be 3 -dehydrovitamin $A_{1}$, Morton \& Creed (1939) observed that administration of $\beta$-carotene resulted in an increase of both retinol and dehydroretinol in some freshwater fish. However, this finding has not yet been confirmed. Grangaud \& Moatti (I95 $8 a, b$ ) reported the conversion of astaxanthin into dehydroretinol in Gambusia holbrooki, but confirmatory reports are yet to appear. The conversion of retinol into dehydroretinol in the eye in freshwater fish has been demonstrated by Naito \& Wilt (1962). These workers have also shown that the liver is unable to convert substantial amounts of retinol into dehydroretinol under conditions of organ culture. Budowski \& Gross $\left(196_{5}\right)$ have reported the conversion of some carotenoids containing at least one 3 -dehydro- $\beta$-ionone ring into dehydroretinol in the mouse. Krishna Mallia, Savitry \& Cama (1970) have similarly reported the formation of dehydroretinol from anhydrolutein in the rat. These findings, however, do not reveal the origin of dehydroretinol from natural carotenoids.

The present work describes the conversion of lutein into dehydroretinol in the freshwater fish, Saccobranchus fossilis, which was made vitamin A-deficient by being fed on a diet of rice and meat. It also shows that $\beta$-carotene or zeaxanthin, when administered to the vitamin A-depleted fish, is not transformed into dehydroretinol.

* Present address: Institute of Marine Biochemistry, Torry, Aberdeen.

+ Present address: Shillong College, Shillong-3, India. 
MATERIALS AND METHODS

\section{Solvents}

Light petroleum (b.p. $\left.40^{\circ}-60^{\circ}\right)(\mathrm{BDH}, \mathrm{A}$ Division of Glaxo Laboratories (India) Ltd, Bombay) was used. Diethyl ether was freshly distilled over reduced iron to remove peroxides. Chloroform was left over calcium chloride, filtered and distilled before use.

\section{Reagents}

Antimony trichloride reagent (Carr-Price reagent) was prepared by dissolving $100 \mathrm{~g}$ $\mathrm{SbCl}_{3}$ (AnalaR; British Drug Houses Ltd, Poole, Dorset) in $400 \mathrm{ml}$ pure dry chloroform. AnalaR KOH (E.Merck AG, Darmstadt, Germany) was used. Other chemicals were of laboratory reagent grade.

Alumina (for chromatographic adsorption analysis, standardized according to Brockmann, activity II-III) was supplied by Sarabhai Merck Ltd, Baroda, India. It was deactivated with known amounts of water, usually $50-80 \mathrm{ml} / \mathrm{kg}$, stirred in slowly under light petroleum. Calcium carbonate for chromatographic adsorption (British Drug Houses Ltd, Poole, Dorset) was heated to $150^{\circ}$, and cooled in a desiccator immediately before use.

Crystalline synthetic $\beta$-carotene (Fluka AG, Buchs SG, Switzerland) and retinyl acetate (Roche Products Ltd, Bombay) were used. Zeaxanthin was isolated from the anthers of Delonix regia (locally grown) by the method previously described (Barua $\&$ Barua, I966). It was purified by repeated chromatography on deactivated alumina and crystallized from methanol (m.p. $205^{\circ}$, uncorrected). Crystalline lutein was obtained as a gift from Professor S. Liaaen-Jensen. Lutein was also isolated from cow-dung as follows.

Cow-dung (500 g) was treated with ethanolic potassium hydroxide ( $100 \mathrm{~g} / 1 ; 500 \mathrm{ml})$ at $60^{\circ}$ for $2 \mathrm{~h}$. The pigment was extracted with diethyl ether thrice. The bulked extract was washed with water to remove alkali, dried over anhydrous $\mathrm{Na}_{2} \mathrm{SO}_{4}$, and the solvent was removed under reduced pressure. The residue was dissolved in benzene $(5 \mathrm{ml})$ and light petroleum $(20 \mathrm{mi})$ was added. The solution was poured on to a column of deactivated alumina $(80 \mathrm{ml}$ water $/ \mathrm{kg})$. The chromatogram was developed with the same solvent mixture. The carotenes flowed down quickly. The main band containing lutein was eluted, after extrusion, with diethyl ether. The solvent was removed under reduced pressure and the residue was dissolved in a small quantity of a mixture of benzene and light petroleum ( $\mathbf{r}: 4$, by volume) and rechromatographed on a short alumina (deactivated by the addition of $80 \mathrm{ml}$ water $/ \mathrm{kg}$ ) column. Lutein contained in the main dark-yellow zone was eluted as before. A portion of lutein was then further purified by thin-layer chromatography on $\mathrm{CaCO}_{3}$ ( $3 \mathrm{~mm}$ thickness) using benzene-light petroleum $(2: 5$, by volume). Two spots were observed. The main spot contained lutein $\left(R_{F}=0.44\right)$ and exhibited maxima at 476,447 , and $422 \mathrm{~nm}$ in light petroleum. The remaining lutein was then purified on a column of $\mathrm{CaCO}_{3}$ using benzene-light petroleum $\left(\mathrm{r}: 4\right.$, by volume). As on thin layers of $\mathrm{CaCO}_{3}$, two compounds were separated and the main band containing lutein was eluted with benzene- 
light petroleum (4:10, by volume). To test the purity, a portion of lutein, purified on the column of $\mathrm{CaCO}_{3}$, was again subjected to thin-layer chromatography on $\mathrm{CaCO}_{3}$ as before; but this time there was no separation into two spots. Purified lutein was then crystallized from methanol at $-5^{\circ}$. The orange-red crystals had m.p. $193^{\circ}$ (uncorrected) and exhibited maxima at 476,447 , and $422 \mathrm{~nm}$ in light petroleum (40-60 $)$.

A sample of authentic lutein was subjected to thin-layer chromatography on plates of $\mathrm{CaCO}_{3}$, as before, from the same solvent mixture, and showed $R_{F}=0.44$. Next, crystals of authentic lutein and lutein from cow-dung were mixed, dissolved in benzene-light petroleum and subjected to thin-layer chromatography on $\mathrm{CaCO}_{3}$ as before. There was no separation and the single spot showed $R_{F}=0^{\circ} 45$.

\section{Recording of absorption spectra}

The visible and ultraviolet absorption spectra of the liver oils and solutions of unsaponifiable fractions were recorded in light petroleum on a Beckman DK-2 spectrophotometer. The amount of retinol or dehydroretinol was then calculated from the gross extinction at 325 and $350 \mathrm{~nm}$ on the basis of $E_{1 \mathrm{~cm}}^{1 \%}$ values of $\mathrm{I}_{32}$ at $325 \mathrm{~nm}$ and $\mathrm{I} 455$ at $350 \mathrm{~nm}$ for retinol and dehydroretinol respectively (Planta, Schwieter, Chopard-dit-Jean, Rüegg, Kofler \& Isler, 1962), no correction being made for irrelevant absorption. The absorption spectra of the antimony trichloride products were recorded in the same instrument as follows.

For a preliminary study, the spectrum of the liver oil or vitamin A solution was recorded using the fastest scanning period of $\mathrm{I}$ min in the region of $400-700 \mathrm{~nm}$. The instrument was then set at 620 or $690 \mathrm{~nm}$, the $100 \%$ transmission was adjusted with pure chloroform to which a drop of acetic anhydride was added. A known volume of the standard liver oil or vitamin A solution was evaporated and the residue was dissolved in chloroform and diluted to the desired strength; I $\mathrm{ml}$ of the solution was pipetted into the sample cell and two drops of acetic anhydride were added. The reference cell containing pure chloroform plus two drops of acetic anhydride and the sample cell were placed in the instrument, and $2 \mathrm{ml}$ of $\mathrm{SbCl}_{3}$ reagent were added by means of an Agla micrometer syringe to the sample cell. The maximum intensity of the blue colour was noted within a few seconds after addition of the reagent. The recording at 620 or $690 \mathrm{~nm}$ was repeated twice more with fresh solutions and the mean value was taken. The amount of retinol or dehydroretinol present in the solution was then calculated from the mean values at 620 and $690 \mathrm{~nm}$ by following the procedure outlined by Cama \& Morton (I953).

The spectra shown in Fig. I have been traced from the originals.

\section{Oral administration of carotenoids}

A portion ( $\mathrm{I}-5 \mathrm{mg}$ ) of the carotenoid was weighed into a small glass bottle, a few drops of Tween-8o (or groundnut oil) were added and the whole was mixed to form a suspension. This was then poured direct into the stomach of the fish by means of a dropper, the mouth of the fish being opened wide.

In another method the carotenoid was mixed thoroughly with Tween-80 as described above, and the suspension was treated with a few $\mathrm{ml}$ of water and stirred 
vigorously to get a homogeneous dispersion. This preparation was then administered to the fish as described above.

In yet another method small pieces of slightly moist goat meat were mixed with the carotenoid dissolved in a drop of groundnut oil and given to the fish.

\section{Administration of carotenoid and retinol}

An aqueous suspension of the carotenoid (or retinol) in 'Tween- 80 was prepared by the method described above, and $0.05 \mathrm{ml}$ or less of this preparation was injected into the fish by means of an Agla micrometer syringe.

Retinol was also given to the fish in small pieces of goat liver, which contains only retinol and no dehydroretinol.

\section{Exiraction of liver oil}

For extraction of liver oil, the fish was killed and the liver was removed and ground with anhydrous $\mathrm{Na}_{2} \mathrm{SO}_{4}$. The extraction was repeated two or three times with light petroleum until the extract was colourless. The bulked extract was evaporated to dryness under reduced pressure; the lipid residue was weighed and then dissolved in a measured volume of light petroleum (usually $25 \mathrm{ml}$ per liver). The differences in concentration of vitamin $A$ in these solutions gave a direct estimate of the decrease or increase of vitamin A content per liver.

\section{Saponification}

To a known amount of liver oil, $\mathrm{xo} \mathrm{ml}$ methanol were added followed by $\mathrm{I} \mathrm{ml}$ of an aqueous solution of $\mathrm{KOH}(500 \mathrm{~g} / \mathrm{l})$. The solution was refluxed at $60^{\circ}$ for $10 \mathrm{~min}$ and cooled, water was added and the product was extracted with diethyl ether. The ether extract was washed free of alkali, dried over anhydrous $\mathrm{Na}_{2} \mathrm{SO}_{4}$ and evaporated to dryness under reduced pressure. The unsaponifiable matter was weighed and then quickly dissolved in a known volume of light petroleum (b.p. 40-60\%).

\section{Fish}

Fish such as Saccobranchus fossilis, Clarius batrachus, Ophicephalus punctatus and Anabas testudineus were found to survive for a long period of about 4 months without taking any food. The liver of one such fish was analysed for vitamin A content, and it was found that the light petroleum extract did not produce any colour with $\mathrm{SbCl}_{3}$ reagent, even when concentrated to about I $\mathrm{ml}$. Of the above-mentioned four species, the first two contain mainly dehydroretinol (Barua \& Singh, 1972) in their liver oil and therefore can be used to investigate the origin of dehydroretinol. Accordingly, $S$. fossilis fish were procured and kept separately in groups of two or three in large glass vessels provided with perforated covers. The water in the vessels was changed almost every day and care was taken to see that no algae grew on the inner surfaces of the vessels. Attempts were made to keep the fish in a healthy condition by supplying them with food free from carotenoids and retinol. Many foods, such as earthworms and snails, which were readily eaten by the fish and were available in plenty, contained carotenoids. It was found, however, that the hungry fish would take rice avidly, and so rice was made the main food. This was supplemented with small quantities of goat 


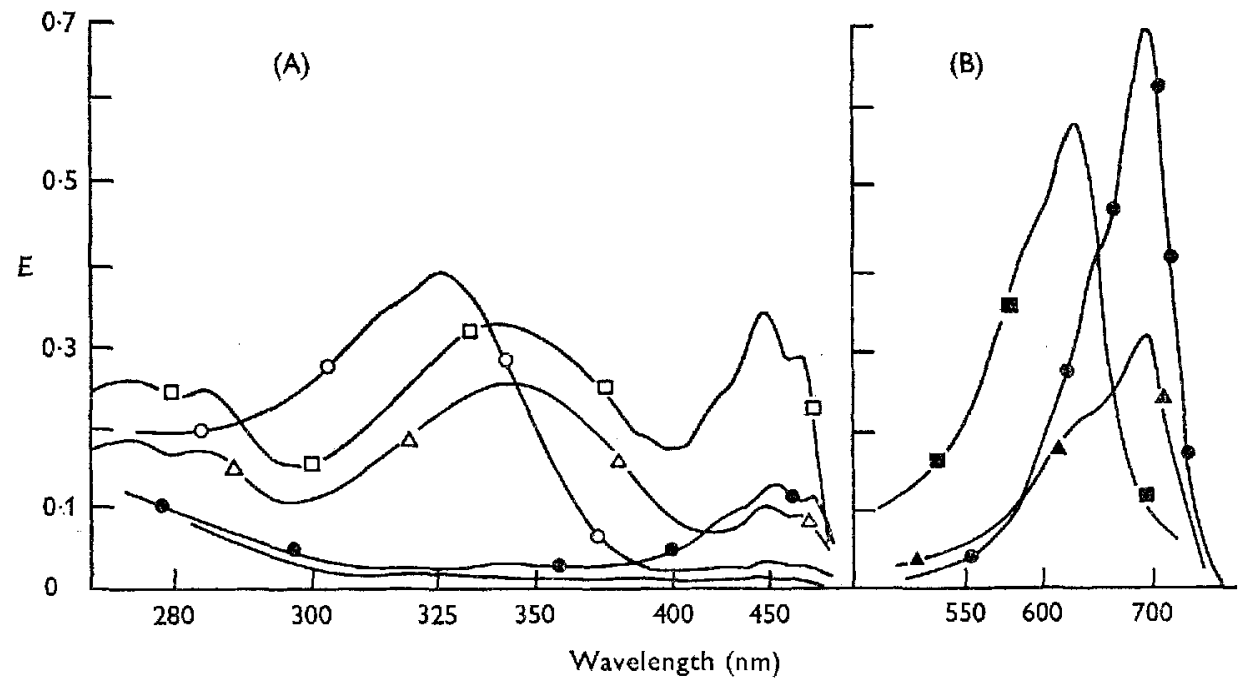

Fig. I. Absorption spectra of: (A) liver oils of Saccobranchus fossilis, freshly caught ( $\square-\square$ vitamin A-depleted ( - - ), and after administration of $\beta$-carotene ( - ), lutein $(\triangle-\triangle)$ or retinol $(\mathrm{O}-\mathrm{O})$; (B) antimony trichloride products of liver oils of Saccobranchus fossilis, freshly caught $(\boldsymbol{\Lambda} \mathbf{\Delta})$, and after administration of lutein $(-)$ or retinol (a- $\mathbf{a})$.

meat (which was found not to contain any detectable amount of retinol in muscle, and contained only retinol in its liver) two or three times a week. The initial vitamin A contents in the livers of freshly caught fish were determined. Although it is customary to saponify the liver oil, because of the small quantities of dehydroretinol to be determined, we found that saponification resulted in appreciable decomposition of dehydroretinol. Consequently in the later experiments, saponification was omitted. A preliminary study showed that the vitamin A content decreased slowly in bigger fish. Therefore small fish were used in later experiments.

\section{RESULTS AND DISCUSSTON}

It was observed that the vitamin A concentration in the smaller fish began to

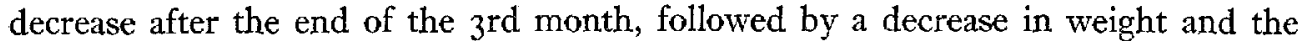
death of some fish. Examination of the liver oil of such fish also revealed that the vitamin $\mathrm{A}$ content was almost negligible; almost no selective absorption in the visible region of the spectrum corresponding to the $\mathrm{SbCl}_{3}$ reaction product was noted. When this condition was reached (Fig. I and Table $\mathrm{I}$ ), $\beta$-carotene in Tween-80 was administered orally to the fish. The fish were dosed for several days in some experiments, but in none was the absorption or conversion of $\beta$-carotene into vitamin $A$ evident. Similarly, zeaxanthin was administered, but with no positive result, indicating formation of dehydroretinol. Several other compounds such as $\alpha$-tocopherol, bile salts, and amino acids, which play some part in the absorption of carotenoids (Deuel, I955), were added to $\beta$-carotene, but without any improvement. The method of administration was changed, and $\beta$-carotene or zeaxanthin mixed with meat was supplied to the 


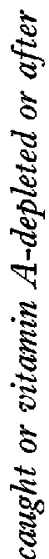

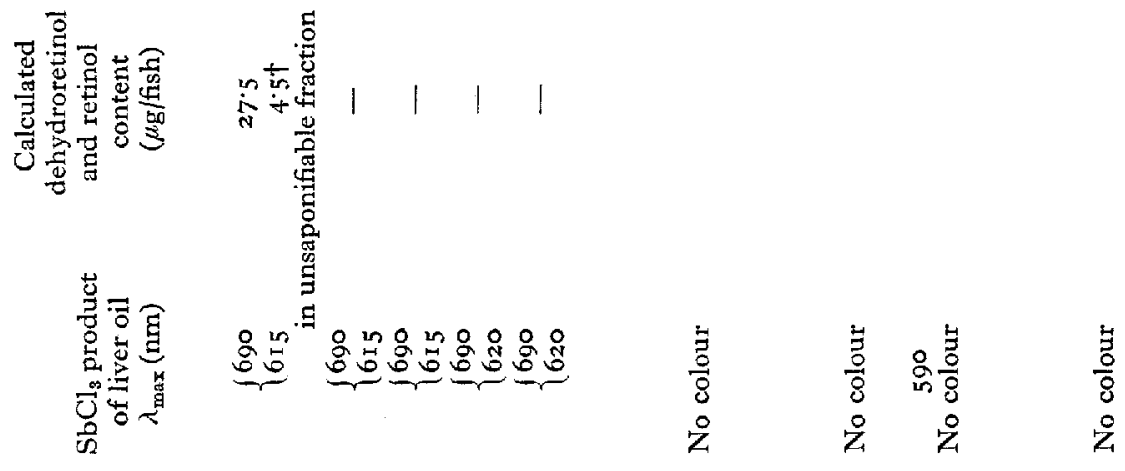

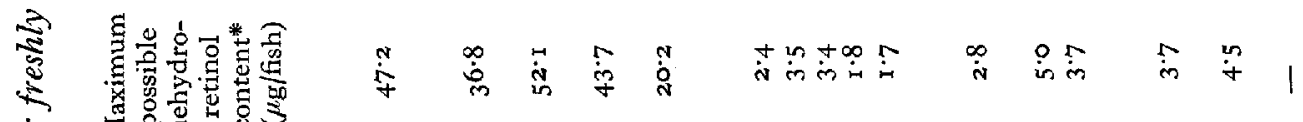

齐

종

:
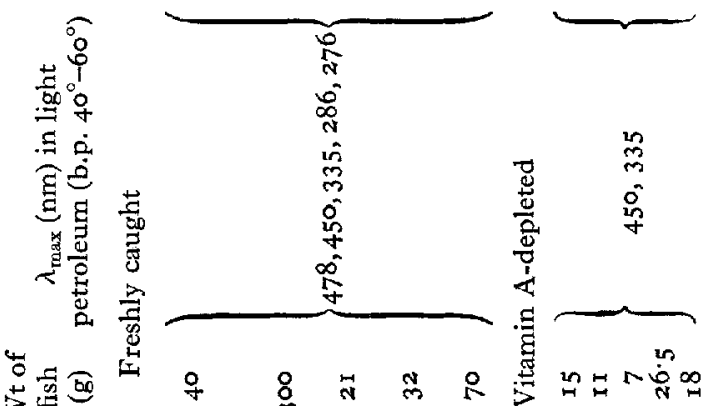

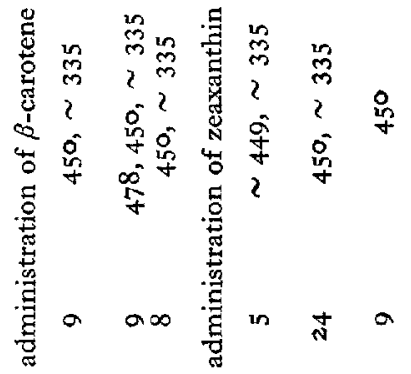

is

恋.

कूष

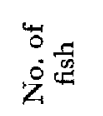

$4 \operatorname{sem} a$

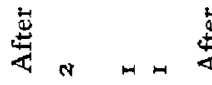

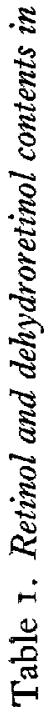

密. :

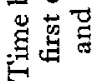

$|1|||$ in

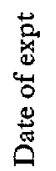

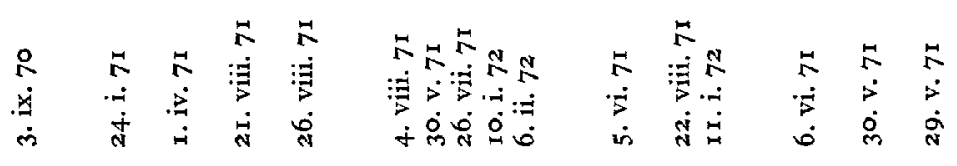

竞
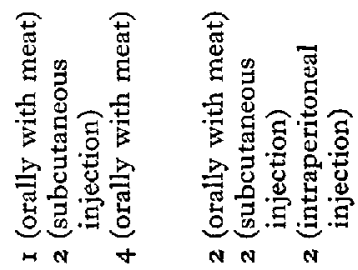
Vol. 30

Formation of vitamin $A$ in a freshwater fish

Wn

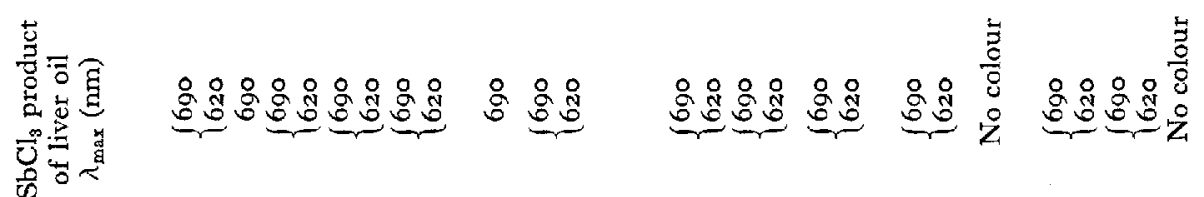

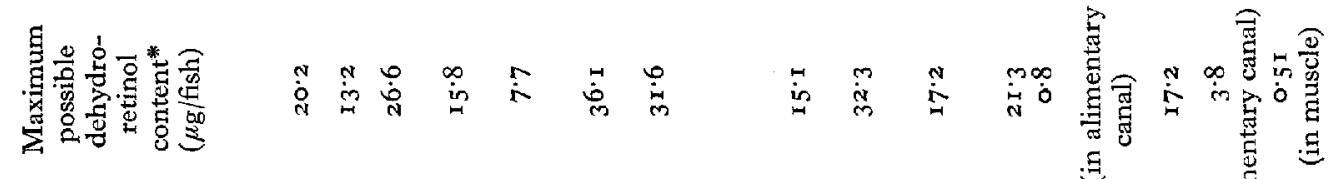

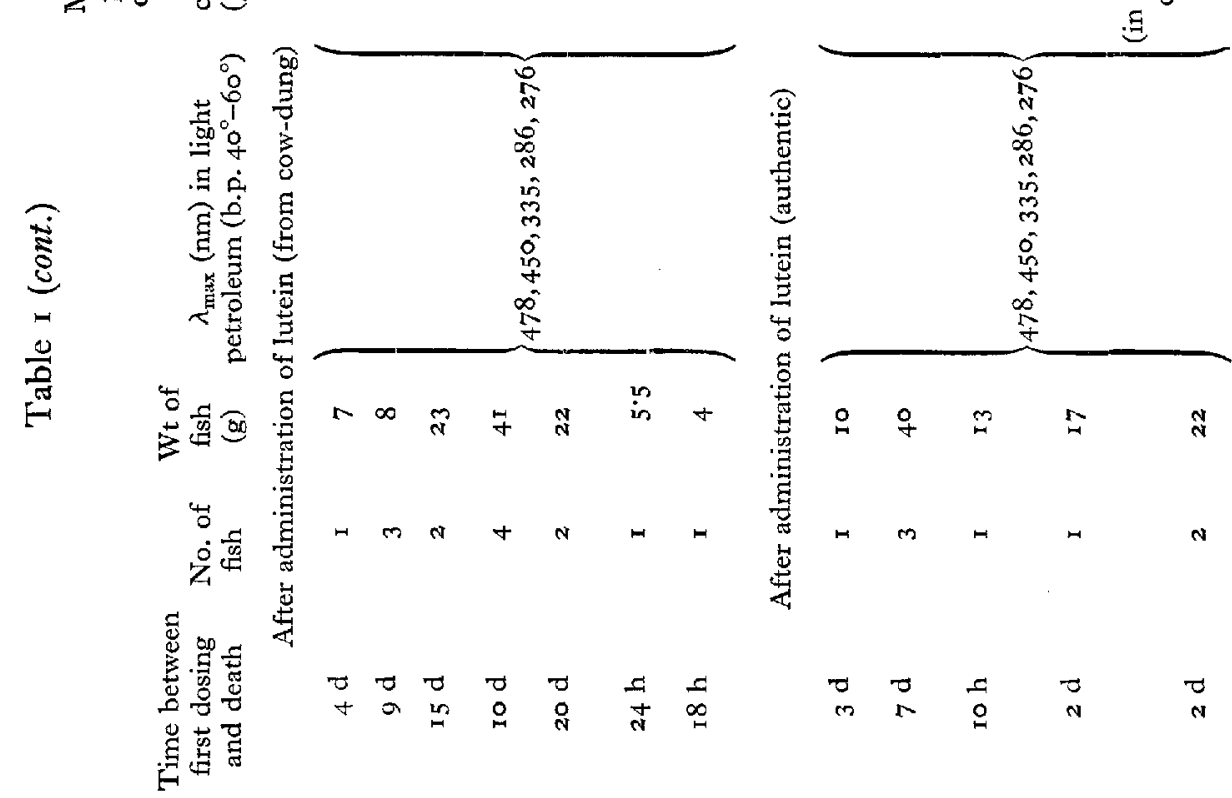

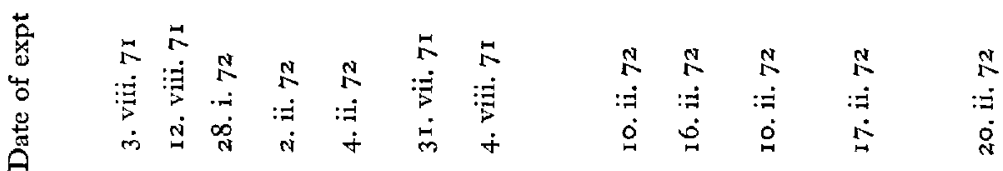

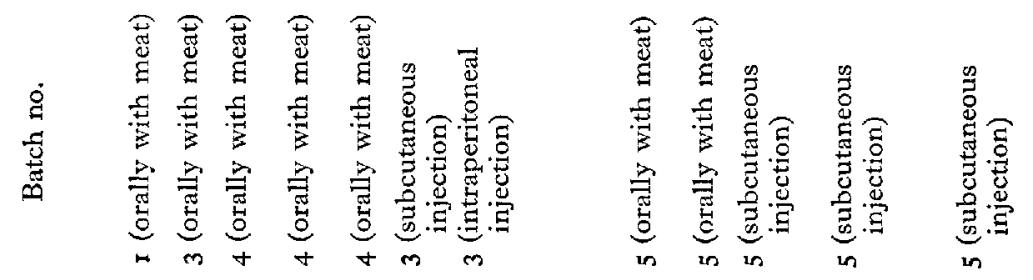




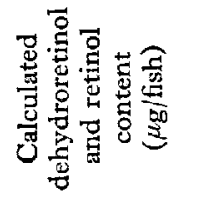

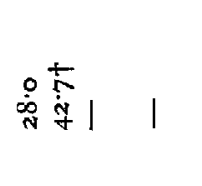

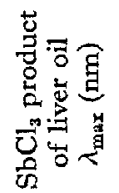

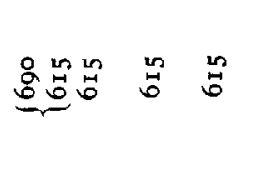

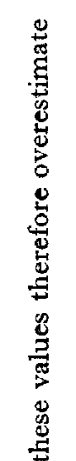

혈

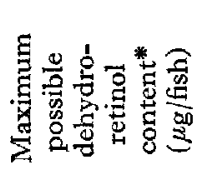

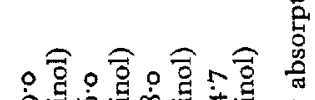
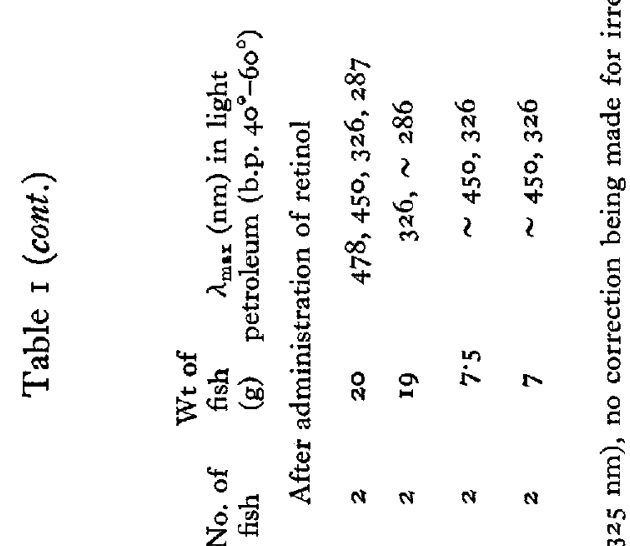

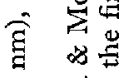

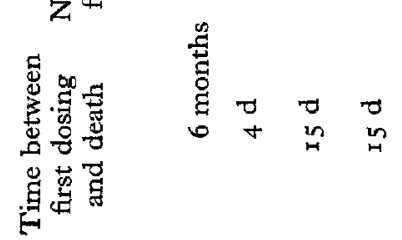

क

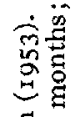

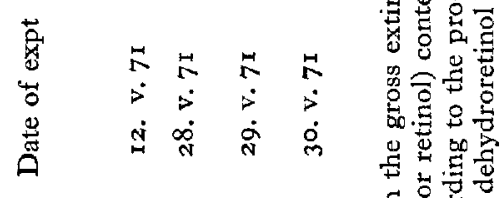

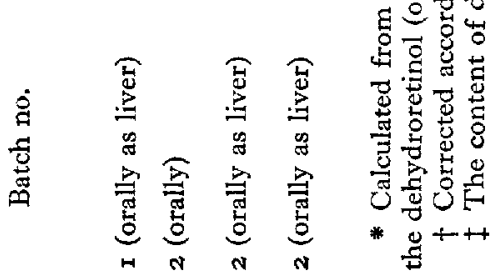


fish. With this method, it was found that only in a few instances were these two carotenoids absorbed as such, and even then to only a slight extent; there was no detectable conversion into vitamin A (Fig. 1 and Table I). The faecal matter excreted in these experiments was deeply coloured and contained unchanged carotenoid. With the other two methods of administration, namely subcutaneous and intraperitoneal injection, no appreciable change of the two carotenoids was observed.

Lutein was then chosen, as this carotenoid has been shown to occur in the liver oils of freshwater fish (Balasundaram, Bamji, Cama, Sundaresan \& Varma, I958; R. K. Barua \& P. G. Nayar, unpublished work). As with $\beta$-carotene and zeaxanthin, lutein was found not to be absorbed or converted into vitamin A when orally administered in Tween-80 or in aqueous suspension in Tween-80. When lutein mixed with meat was supplied to the vitamin A-depleted fish, it was converted into dehydroretinol which accumulated in the liver. There were marked differences in the amount of dehydroretinol in the liver oils of depleted and lutein-dosed fish as judged by the increases in ultraviolet absorption and, more specifically, in the colour reactions (Table $\mathrm{I}$ ). Whereas this change was noted in none of the experiments performed with $\beta$-carotene or zeaxanthin, lutein was converted into dehydroretinol in all the experiments. Dosing of the vitamin A-depleted fish with subcutaneous and intraperitoneal injections of lutein as an aqueous dispersion in Tween-80 was not successful in all the experiments, as the fish could not tolerate the injection, probably owing to their small size, and died in most of the experiments within an hour or two. A few experiments were, however, successful, and we noted that, in some such fish injected with lutein, not only the liver but also the small intestine contained appreciable amounts of dehydroretinol (one example is given in Table $x$ ). The formation of dehydroretinol was detected from the ultraviolet spectrum (maxima at 340 (broad), 286 and $276 \mathrm{~nm}$; Fig. I) and $\mathrm{SbCl}_{3}$ product $\left(\lambda_{\max } 690 \mathrm{~nm}\right.$; Fig. I $)$ of the liver oil.

For further identification of dehydroretinol, liver oil from lutein-dosed fish was chromatographed on a column of deactivated alumina by the procedure outlined by Barua \& Morton (1949). A small amount ( $6 \mu \mathrm{g}$, calculated from the gross ultraviolet extinction at $328 \mathrm{~nm}$ ) of retinyl ester $\left(\lambda_{\max } 328 \mathrm{~nm}, \mathrm{SbCl}_{3}\right.$ product $\left.\lambda_{\max } 6 \mathrm{I}_{5} \mathrm{~nm}\right)$ was detected in the eluate with light petroleum. Dehydroretinyl ester $\left(3^{6} \mu \mathrm{g}\right.$, calculated from gross ultraviolet extinction at $350 \mathrm{~nm}$ ) was also eluted with light petroleum. Thus purified, dehydroretinyl ester showed $\lambda_{\max } 345^{-35^{2}}$ (broad), 287 and $276 \mathrm{~nm}$, and produced a green colour with $\mathrm{SbCl}_{3}$ reagent showing $\lambda_{\max } 690 \mathrm{~nm}$. We were, however, surprised to detect retinol along with dehydroretinol in the liver of these lutein-dosed fish. Retinol, which should have been formed from $\beta$-carotene, was not detected in any of the $\beta$-carotene dosed fish. This shows that both retinol and dehydroretinol can be formed from lutein, and therefore the biogenesis of vitamin $A$ in this species of fish, $S$. fossilis, seems to be quite different from that in others.

Examination of the structures of lutein and zeaxanthin (Fig. 2) shows that lutein has an allylic hydroxy group, whereas zeaxanthin does not. In lutein the elimination of an allylic hydroxy group as water, with the consequent introduction of a double bond and a rearrangement of the conjugated system could take place. Zeaxanthin, lacking an allylic hydroxy group, would be resistant to such dehydration. 
<smiles>CC1=C(/C=C/C(C)=C/C=C/C(C)=C/C=C/C=C(C)/C=C/C=C(C)/C=C/C=C2CC(O)CC(C)(C)C(/C=C/C(C)=C/C=C/C(C)=C/CO)=C2C)C(C)(C)CC(O)C1</smiles>

Fig. 2. Structure of (I) $\beta$-carotene, (II) zeaxanthin, (III) lutein and (IV) dehydroretinol.

Other experiments were also carried out to see if retinol is converted into dehydroretinol by $S$. fossilis. In one experiment two of these fish were given a diet of rice and goat liver for 4 months, then rice alone for 2 months. The fish were then killed and their liver oil was analysed for vitamin A. It was found to contain mainly retinol $\left(\lambda_{\max }\right.$ $326, \sim 287 \mathrm{~nm}$ ). The maximum possible amount of retinol, calculated from gross extinction at $325 \mathrm{~nm}$ with no correction being made for irrelevant absorption, is shown in Table $\mathrm{I}$ as $\mathrm{I} 89 \mu \mathrm{g}$ and is an overestimation. However, the $\mathrm{SbCl}_{3}$ product showed a prominent band at $690 \mathrm{~nm}$, and from the colour reaction an amount of 28 $\mu \mathrm{g}$ dehydroretinol/fish was calculated as against $42 \cdot 7 \mu \mathrm{g}$ retinol/fish (Table $\mathrm{I}$ ). The two fish were not made vitamin A-deficient before being given the diet of rice and goat liver. Thus we did not know whether the dehydroretinol was derived from the endogenous retinol or from that supplied in food. However, it is unlikely that this substantial portion of dehydroretinol was the remains of what was originally present. The conversion of retinol into dehydroretinol cannot, therefore, be ruled out; probably it does take place, but very slowly.

In a later experiment two fish were first made vitamin A-deficient by giving them a diet of rice and meat alone; an aqueous dispersion of retinyl acetate in Tween-80 was given orally to one and by subcutaneous injection to the other. In both fish retinol was deposited in the liver. The amount of dehydroretinol estimated from the $\mathrm{SbCl}_{3}$ colour by the procedure of Cama \& Morton (1953) was negligible. Minced pieces of goat liver were supplied for $7 \mathrm{~d}$ along with rice to some other fish made vitamin A-deficient; examination of the liver oil on the 15 th day showed the presence of retinol but not of dehydroretinol as judged from the ultraviolet spectrum (no band or inflexion was present at $287 \mathrm{~nm}$; Fig. I) and the $\mathrm{SbCl}_{3}$ colour absorption (specific absorption at 690 nm was negligible; Fig. I). No substantial amount of dehydrotetinol was detected in 
Table 2. Recovery of dehydroretinol after administration by subcutaneous injection of lutein to Saccobranchus fossilis

$\begin{array}{ccccc}\begin{array}{c}\text { No. of } \\ \text { fish }\end{array} & \begin{array}{c}\text { Time between } \\ \text { first dosing } \\ \text { and death }\end{array} & \begin{array}{c}\text { Lutein } \\ (\mu \mathrm{g})\end{array} & \begin{array}{c}\text { Dehydroretinol } \\ (\mu \mathrm{g})^{*}\end{array} & \begin{array}{c}\text { Conversion } \\ \text { ratio }\end{array} \\ \text { I } & \text { Io h } & 400 & 7 \cdot 4 \text { (in liver) } & 0.019 \\ \text { I } & 2 \mathrm{~d} & 800 & 2.3 \text { (in liver) } & 0.003 \\ 2 & 2 \mathrm{~d} & 800 & \mathbf{2 2 . 2} \text { (in liver) } & 0.028 \\ 2 & \text { 2 d } & 800 & \mathbf{5 . 5} \text { (in alimentary } & 0.007 \\ & & & \text { canal) }\end{array}$

* Calculated from $\mathrm{SbCl}_{3}$ blue colour according to the method of Cama \& Morton (1953).

any of the experiments with vitamin A-depleted fish. From the results of these experiments it can, therefore, be concluded that retinol cannot be converted rapidly into dehydroretinol by $S$. fossilis but, as pointed out before, the process can probably occur very slowly.

From the results of the experiments, some of which are shown in Table $\mathbf{I}$, it is concluded that lutein is the natural carotenoid that is transformed into dehydroretinol. From Table I, it can be seen that the liver oils of fish depleted of vitamin A and of most of those given $\beta$-carotene and zeaxanthin showed some absorption at $35^{\circ} \mathrm{nm}$, and the maximum possible dehydroretinol content has been calculated in Table I on the assumption that all the absorption at $350 \mathrm{~nm}$ was contributed by dehydroretinol. Since other material would contribute to the extinction value at $35^{\circ} \mathrm{nm}$, these values in Table I calculated from the ultraviolet measurements overestimate the true dehydroretinol content. Although in many extracts the ultraviolet extinction indicates that there could be a very small amount of dehydroretinol present, no absorption in the $600-700 \mathrm{~nm}$ region of the visible spectrum was noted in their reaction with $\mathrm{SbCl}_{3}$, even when very concentrated solutions were used, and this indicated the absence of vitamin $\mathrm{A}$ in these liver oils. The liver oils of lutein-dosed fish, on the other hand, produced intense colour with $\mathrm{SbCl}_{3}$ (Fig. I).

Attempts were made to find out the amount of the carotenoids absorbed and the percentage conversion of lutein into dehydroretinol. However, the method of oral administration was such that a considerable amount of the carotenoid went into the water of the vessel containing the fish during feeding and, therefore, the amount of the carotenoid actually taken up by the fish could not be determined. In experiments in which the method of dosing was by injection, the amount of lutein administered, and hence the percentage conversion into dehydroretinol, was known in a few experiments, the results of which are shown in Table 2.

We are grateful to Professor N. N. Siddhanta, Head of the Department of Chemistry, for encouragement and for providing the necessary facilities. The permission accorded to two of us (H. T. S. and R. C. D.) to work in the Chemistry Laboratory is also gratefully acknowledged. 'Thanks are due to Professor S. Liaaen-Jensen, Organic Chemistry Laboratories, Norwegian Institute of Technology, Trondheim, for the generous gift of lutein. 


\section{REFERENCES}

Balasundaram, S., Bamji, M. S., Cama, H. R., Sundaresan, P. R. \& Varma, T. N. R. (I958). \%. biol. Chem. 233, 827.

Barua, R. K. \& Barua, A. B. (1966). Biochem. F. ror, 250.

Barua, R. K. \& Morton, R. A. (1949). Biochem. F. 45, 308.

Barua, A. B. \& Singh, H. T. (1972). Indian Y. Biochem. Biophys. 9, 128.

Budowski, P. \& Gross, J. (1965). Nature, Lond. 206, 1254.

Cama, H. R. \& Morton, R. A. (1953). Analyst, Lond. 78, 74.

Deuel, H. J. Jr (1955). Lipids Vol. 2, p. 282. New York: Interscience Publishers, Inc.

Ganguly, J. \& Murthy, S. K. (1967). In The Vitamins 2nd ed. Vol. I, p. 146 [W. H. Sebrell Jr and R. S. Harris, editors]. New York: Academic Press.

Grangaud, R. \& Moatti, J. P. (1958a). C. r. Séanc. Soc. Biol. 152, 1235.

Grangaud, R. \& Moatti, J. P. (1958b). C. r. Séanc. Soc. Biol. 152, 1245.

Krishna Mallia, A., Savitry, K. N. \& Cama, H. R. (I970). Paper read at the Convention of Chemists, Indian Institute of Technology, Madras, 30 November-4 December 1970.

Morton, R. A. \& Creed, R. H. (1939). Biochem. F. 33, 318.

Naito, K. \& Wilt, F. H. (1962). F. biol. Chem. 237, 3060 .

Planta, C. V., Schwieter, U., Chopard-dit-Jean, L., Rüegg, R., Kofler, M. \& Isler, O. (1962). Helv. chim. Acta 45, 548. 